\title{
Maximum Power Point Tracking of DC To DC Boost Converter Using Sliding Mode Control
}

\author{
${ }^{1}$ R.Anusuyadevi, ${ }^{2}$ P.Suresh Pandiarajan, ${ }^{3}$ J.Muruga Bharathi \\ ${ }^{1,2,3}$ Assistant Professor \\ Department of Electronics and Communication Engineering \\ P.S.R.Rengasamy College of Engineering for Women, Sivakasi, Tamilnadu,India.
}

\begin{abstract}
A sliding mode controller is used to estimate the maximum power point as a reference for it to track that point and force the PV system to operate in this point. In sliding mode control, the trajectories of the system are forced to reach a sliding manifold of surface, where it exhibit desirable features, in finite time and to stay on the manifold for all future time. The load is composed of a battery bank. It is obtained by controlling the duty cycle of a DC-DC converter using sliding mode control. This method has the advantage that it will guarantee the maximum output power possible by the array configuration while considering the dynamic parameters solar irradiance and delivering more power to charge the battery.

The proposed system with sliding mode control is tested using MATLAB / SIMULINK platform in which a maximum power is tracked under constant and varying solar irradiance and delivered to the battery which increasing the current that is charging the battery and reduces the charging time.
\end{abstract}

Keywords - Sliding manifold, Solar irradiance, Photo voltaic system.

\section{INTRODUCTION}

Photo Voltaic (PV) systems are used as energy source in many cases. Most commonly applied PV systems can be found in remote and rural areas where no public grid is available. Photovoltaic is the technology that uses solar cells or an array of them to convert solar light directly into electricity. The power produced by the array depends directly form factors that are not controlled by the human being as the cell's temperature and solar irradiance. Usually the energy generated by these solar cells is used to provide electricity to a load and the remaining energy is saved into batteries. Photovoltaic cells have a single operating point where the values of the current and voltage of the cell result in a maximum power output.

By connecting the PV cell directly to a load or a battery, the output power can be severely reduced due to load mismatching or, in case of a battery, load voltage mismatching. Since this operating point depends on factors like temperature, solar irradiance and load impedance, a device capable of tracking the maximum power point and force the PVM to operate at that point is required. A maximum power point tracker (MPPT) is a device capable of search for the point of maximum power and, using DC-DC converters, extracts the maximum power available by the cell [3-6]. By controlling the duty cycle of the switching frequency of the converter we can change the equivalent voltage of the cell and by that, its equivalent resistance into the one in which the PVM is in the maximum power operating point[1-2].

\subsection{Photo Voltaic System}

\section{SYSTEM REQUIREMENTS AND TECHNICAL BACKGROUND}

A typical small photovoltaic power system (off-grid) can contain the following components: solar PV array, with a number of series/parallel interconnected solar modules and protection elements, a DC/DC converter, a DC/AC inverter and a control system.[3-5]

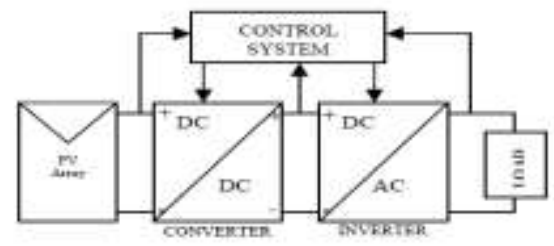

Figure.A.1 Basic Structure of Photo Voltaic System

The target of control system is that the PV array will maximize the electrical power with a given irradiance. The control should guarantee that the dc power will be transformed with high efficiency to the load. In order to archive the maximum power point (MPP) of the PV array, it is necessary maintain it at their optimum 
point operating. The MPP varies with the solar radiation and the temperature. The characteristic curves specify a unique operating point at which maximum possible power is delivered. At the MPP, the PV system operates at its highest efficiency.

A control that regulates the voltage of the DC/DC converter and maximizes the power generated by the photovoltaic array will be presented. The system consists of three closed loops, two inner loops and one outer loop. The DC/DC converter has a control loop which regulates the output voltage irrespective of the input voltage variations, and a sliding mode control that searches the maximum power point of the PV array. The proposed system has an independent control loop for the PWM inverter.

In this control system, it is necessary to measure the PV array output power and to change the duty cycle of the DC/DC converter control signal. So, the PV array output power is measured and compared to the previous PV array output power. Depending on the result of the comparison, the optimal reference current of sliding mode control is changed and the process is repeated until the maximum power is reached.[7-9]

\subsection{DC to DC Boost Converter}

The state-space model of the boost converter that will be used to evaluate the sliding mode control is presented. A boost converter is simply is a particular type of power converter with an output DC. This type of circuit is used to 'step-up' a source voltage to a higher, regulated voltage, allowing one power supply to provide different driving voltages. The basic boost converter circuit consists of only a switch (typically a transistor), an inductor, and a capacitor

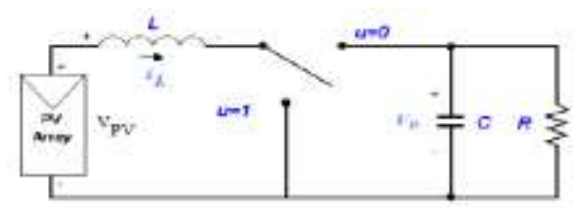

Figure.B.1 Boost Converter

Applying Kirchhoff's rules around the loops, it can obtain the ideal mathematical model of this circuit: $L \frac{d i_{L}}{d t}=V_{p v}-v_{o}(1$

$c \frac{d v_{s}}{d t}-i_{L}(1-w)$
$-\frac{v_{s}}{R}$

where $\mathrm{i}_{\mathrm{L}}$ is the current across the inductor, $\mathrm{v}_{\mathrm{o}}$ is the voltage in the capacitor. Parameters $\mathrm{R}, \mathrm{L}$ and $\mathrm{C}$ are supposed to be known constants. $\mathrm{u} \in\{0,1\}$ defines the switch position and $\mathrm{V}_{\mathrm{PV}}$ is voltage supplied by photovoltaic array. The gain from the boost converter is directly proportional to the duty cycle ( D ), or the time the switch is 'on' each cycle.

$$
\frac{v_{o}}{V_{P V}}=\frac{1}{1-D}
$$

When boost converter is used in PV applications, the voltage input change continuously with atmospheric conditions. Therefore, the duty cycle should change to track the maximum power point of photovoltaic array. This converter should support input voltages in a wide range from 100 to $325 \mathrm{~V}$. Under such conditions, the duty ratio $\mathrm{D}$ is adjusted to regulate the output voltage at $400 \mathrm{~V}$. For the given range, $\mathrm{D}$ is in a range of [0.76-0.20] and the output current is maximum when $\mathrm{D}=0.33$. The 400 Volts obtained at boost converter are applied to an IGBT two-level inverter to generate a sinusoidal output voltage of $50 \mathrm{~Hz}$. The IGBT inverter uses Pulse Width Modulation (PWM) at a $1050 \mathrm{~Hz}$ carrier frequency. The circuit is discretized at a sample time of $1 \mu \mathrm{s}$. The IGBT inverter is controlled with a PI regulator in order to maintain to $230 \mathrm{Vrms}, 50 \mathrm{~Hz}$ at the load terminals.

\subsection{Maximum Power Point Tracking}

A technique to utilize effectively the photovoltaic is known as a maximum-power- point tracking (MPPT) method, which makes it possible to acquire as much power as possible from the photovoltaic. Since an electric characteristic of the output power to the operating voltage or current has a convex property, there exists only one optimum operating point on the power-voltage (or current) curve. The MPPT is a method to let the controller operate at the above-mentioned optimum operating point. There have been various kinds of MPPT methods reported and the most common technique of them is a hill-climbing method, which seeks the optimum operating point by changing the operating voltage or current until the power becomes the maximum. Therefore, this method essentially requires power calculation using both the voltage sensor and the current sensor. 


\subsubsection{Working of MPPT}

MPPT is not a mechanical tracking system that "physically moves" the modules to make them point more directly at the sun [3-6]. MPPT is a fully electronic system that varies the electrical operating point of the modules so that the modules are able to deliver maximum available power. Additional power harvested from the modules is then made available as increased battery charge current. MPPT can be used in conjunction with a mechanical tracking system, but the two systems are completely different.

To understand how MPPT works, let's first consider the operation of a conventional (non-MPPT) charge controller. When a conventional controller is charging a discharged battery, it simply connects the modules directly to the battery. This forces the modules to operate at battery voltage, typically not the ideal operating voltage at which the modules are able to produce their maximum available power.

Rather than simply connecting the module to the battery, the patented MPPT system in a Solar Boost charge controller calculates the voltage at which the module is able to produce maximum power.[8-9].

\subsection{Sliding Mode Control}

Sliding mode control (SMC) is an important robust control approach. It is method which transformed a higher-order system into first-order system. For the class of systems to which it applies, sliding mode controller design provides a systematic approach to the problem of maintaining stability and consistent performance in the face of modeling imprecision. On the other hand, by allowing the tradeoffs between modeling and performance to be quantified in a simple fashion, it can illuminate the whole design process [11$15]$.

Essentially, sliding mode control utilizes discontinuous feedback control laws to force the system state to reach, and subsequently to remain on, a specified surface within the state space (the so called sliding or switching surface). The system dynamic when confined to the sliding surface is described as an ideal sliding motion and represents the controlled system behavior.

The design of the sliding mode control law can be divided in two phases:

1. Phase 1 consists in the construction of a suitable sliding surface so that the dynamic of the system confined to the sliding manifold produces a desired behavior;

2. Phase 2 entails the design of a discontinuous control law which forces the system trajectory to the sliding surface and maintains it there.

\subsubsection{Sliding Mode Voltage Controlled (SMVC) Buck Converter}

One of the most important features of sliding mode regime in variable structure systems (VSS) is the ability to achieve responses that are independent of the system parameters, the only limit being the canonical form description of the system. From this point of view, the Buck DC/DC converter is suitable for the application of the SMC. The main advantage of this approach is that the switching frequency is constant under all operating conditions, and it is easily controllable through varying the ramp signal. Basically, there are two methods of implementing this constant frequency operation.

Sliding mode control implies that control actions are discontinuous state functions, which may easily be implemented by conventional power converters with On-Off as the only admissible operation mode. Sliding mode control has been proved to be applicable to a wide range of problems in robotics, electric drives and generators, process control, vehicle and motion control. A sliding mode controller for buck converter is proposed in this paper. A simple and easy to follow design procedure is described. Simulation results are presented to explore the potentials of Sliding mode control for Buck converter.[10-12]

\section{PROPOSED SYSTEM}

\subsection{Maximum Power Point Tracking Using Sliding Mode Controller}

The proposed model will guarantee the extraction of the maximum power that can be produced by the PVM while regulating the load voltage to the battery's voltage. That way we can have a workable load voltage that can be connected to an inverter while matching the load resistance to the PV optimal resistance. The system use a PV array $(s \times p)$ composed of $s$ in series cells and $p$ in parallel cells. It is then connected to a DC-DC converter in order to increase or decrease the desired voltage. It is then connected directly to the load, which is composed of a $12 \mathrm{~V}$ battery. The duty cycle of the converter is controlled by a sliding mode controller [1]. 


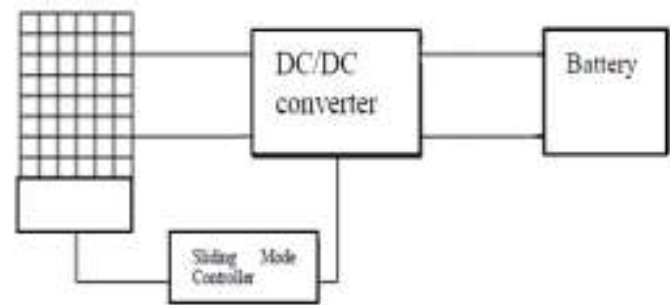

Fig.E.1 Photo Voltaic Cell with Sliding Mode Controller

\subsection{PV Model Analysis}

A PV model was proposed where analytical equations relates the PV output current with the PV output voltage, temperature and solar irradiance over the PV module. It also shows experimental results validating the accuracy and effectiveness of the proposed model. An advantage of this model is that all the needed information can be found in the manufacturer's data sheet. Also it shows how the PV power is affected by changes in the temperature and solar irradiance.

\section{SimUlation RESUlts}

The system parameters used for simulation: PV MODULE (Short Circuit Current=5.45A, Open Circuit Voltage $=22.2 \mathrm{~V}$, Current at $\mathrm{P}_{\max }=4.95 \mathrm{~A}$, Voltage at $\mathrm{P}_{\max }=17.2 \mathrm{~V}$ ), MOSFET (FET Resistance $\mathrm{R}_{\mathrm{on}}=0.1 \Omega$, Internal Diode Resistance $\mathrm{R}_{\mathrm{d}}=0.01 \Omega$, Snubber Resistance $\mathrm{R}_{\mathrm{s}}=0.01 \mathrm{~mA}$, Snubber Capacitance Cs=inf), Diode (Resistance $\mathrm{R}_{\mathrm{on}}=0.01 \Omega$, Forward Voltage $\mathrm{V}_{\mathrm{f}}=0.8 \mathrm{~V}$, Snubber Resistance $\mathrm{R}_{\mathrm{s}}=500 \Omega$, Snubber Capacitance $C s=250 \mathrm{nF}$ ) Battery Type=Nickel-Metal-Hydride,

Nominal Voltage $=12 \mathrm{~V}$, Rated Capacity $=10 \mathrm{Ah}$, Initial State-of-Charge $=30 \%$. Load Resistance $\mathrm{R}_{\mathrm{L}}=1 \Omega$, Load Capacitance $\mathrm{C}_{\mathrm{L}}=4700 \mu \mathrm{F}$.

The simulation block diagram of PV System for Maximum Power Point Tracking using Sliding Mode Controller is shown in Figure F.1.

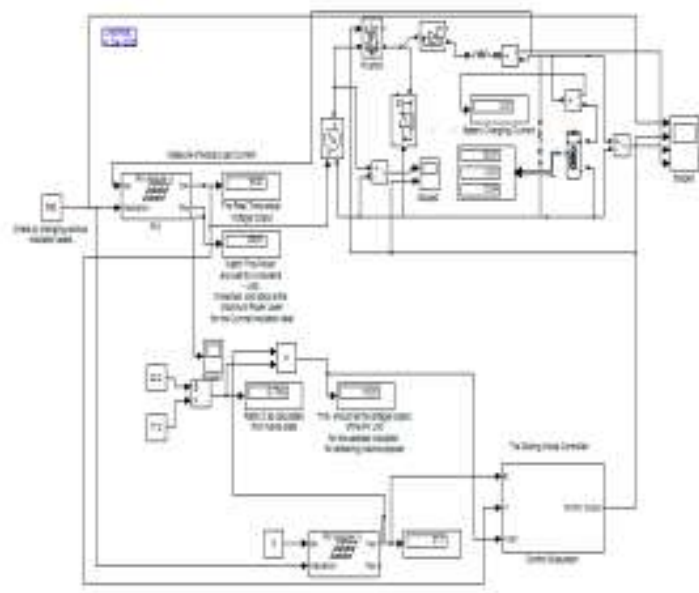

Figure 4.1 Simulation Block Diagram of PV systems for Maximum Power Point Tracking using Sliding Mode Controller.

The subsystem of the PV Module is shown in the figure 4.2

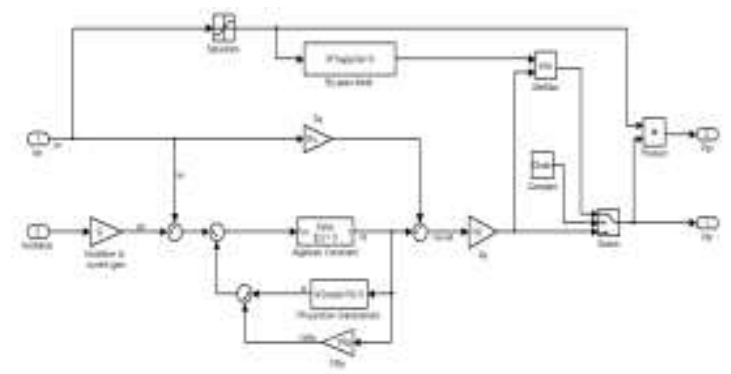

Fig. 4.2 Simulation block diagram of PV Module Subsystem. 
The Simulation Diagram of Sliding Mode Controller of the PV System is shown in Figure 4.3.

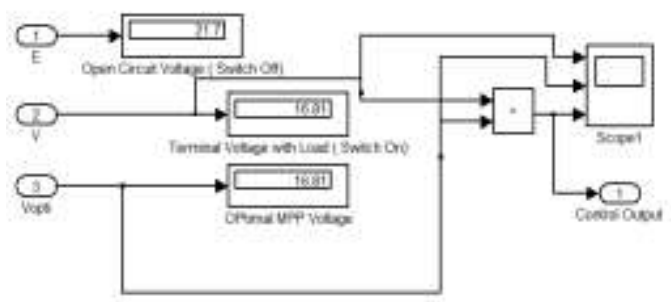

Fig.4.3 Simulation Diagram of Sliding Mode Controller

\subsection{Output Waveforms for Various Values of Solar Irradiances-Insolation}

The output waveforms of the PV system which is connected to the Battery (load) with the help of DCDC converter, in which the input given as Insolation level is 900 are shown in Figure 4.4.

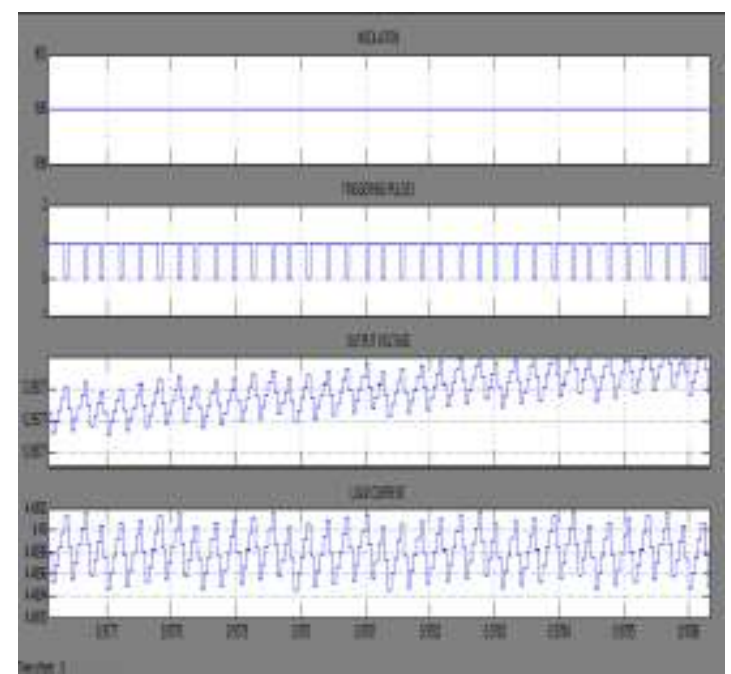

The output waveforms for the Sliding Mode Controller of the PV system with the input Insolation level 900 are shown in Figure 4.5.

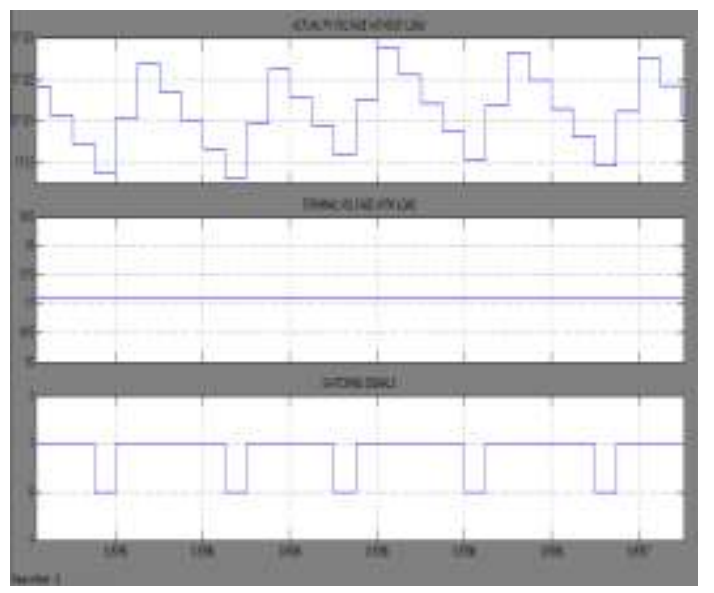

\subsection{Comparison of Results}

When the simulation starts the PVM is not connected, the PVM output voltage will be equal to its open circuit voltage. The maximum power is tracked for various insolation levels in which the optimum Maximum Power Point voltage is obtained by multiplying the open circuit voltage of the system and the ratio of open circuit voltage and the voltage at $\mathrm{P}_{\max }$ of the PV module.

The Comparison of various values of the input and output parameters are compared in Table G.1. 
Table G.1 Comparison of results

\begin{tabular}{|c|c|c|c|c|}
\hline & $\begin{array}{c}\text { OPEN } \\
\text { CIRCUIT } \\
\text { VOLTAGE } \\
\text { INSOLATION } \\
\text { OFF })\end{array}$ & $\begin{array}{c}\text { OPTIMAL } \\
\text { MPP } \\
\text { VOLTAGE }\end{array}$ & $\begin{array}{c}\text { TERMINAL } \\
\text { VOLAGE } \\
\text { WITH } \\
\text { LOAD } \\
\text { (SWITCH } \\
\text { ON) }\end{array}$ & $\begin{array}{c}\text { MAXIMUM } \\
\text { POWER } \\
\text { OUTPUT }\end{array}$ \\
\hline 900 & $22.10 \mathrm{~V}$ & $17.12 \mathrm{~V}$ & $17.12 \mathrm{~V}$ & $76.87 \mathrm{~W}$ \\
\hline 800 & $21.98 \mathrm{~V}$ & $17.03 \mathrm{~V}$ & $17.03 \mathrm{~V}$ & $68.31 \mathrm{~W}$ \\
\hline 700 & $21.85 \mathrm{~V}$ & $16.93 \mathrm{~V}$ & $16.93 \mathrm{~V}$ & $59.54 \mathrm{~W}$ \\
\hline 600 & $21.70 \mathrm{~V}$ & $16.81 \mathrm{~V}$ & $16.81 \mathrm{~V}$ & $50.61 \mathrm{~W}$ \\
\hline 500 & $21.51 \mathrm{~V}$ & $16.67 \mathrm{~V}$ & $16.67 \mathrm{~V}$ & $41.58 \mathrm{~W}$ \\
\hline
\end{tabular}

When the step response is given as the input, if insolation can be given in the range of 800 to 500 , the maximum power obtained first is $68.31 \mathrm{~W}$ and slowly reduces to $41.58 \mathrm{~W}$ finally at the settling value of insolation 500 .

\section{CONCLUSION}

The investigation demonstrates that the proposed sliding mode controller uses a non inverting BuckBoost converter in order to easily change the operation mode of the converter that can be necessary if the optimal voltage of the PV module is lower than the battery voltage. The proposed algorithm is capable of calculating the optimal voltage with little error.

The proposed controller only requires the array output voltage and the optimal voltage which is continuously computed. From the simulation results is evident that a maximum power is tracked and achieved by the proposed sliding mode controller under constant and varying solar irradiance delivered with the losses in the converter, to the battery increasing the current that is charging the battery which, eventually, will reduce the charging time.

\section{References}

[1] Emil A. Jimenez Brea, Eduardo I. Ortiz-Rivera, Andres Salazar-Llinas, Jesus Gonzalez-Llorente, May 2010, "Simple Photovoltaic Solar Cell Dynamic Sliding Mode Controlled Maximum Power Point Tracker for Battery Charging Applications", IEEE Transactions on power electronics, Vol. No.978-1-4244-4783-1, pp. 666-671.

[2] K. N. Hasan, M. E. Haque and M. Negnevitsky, 2008, 'Control Of Energy Storage Interface With A Bidirectional Converter For Photovoltaic Systems" Australasian Universities Power Engineering Conference.

[3] Wu Libo, Zhao Zhengming, Liu Jianzheng, Dec. 2007, “A Single-Stage Three Phase Grid-Connected Photovoltaic System With Modified MPPT Method and Reactive Power Compensation”, Energy Conversion, IEEE Transaction on Vol. 22, Issue 4, pp. 881 886.

[4] 1-Song Kim, 2007, "Robust Maximum power point tracker using sliding mode controller for the three-phase grid-connected photovoltaic system”, .Solar Energy 81, pp. 415-414

[5] Il-Song Kim, Myung-Bok Kim, Myung-Joong Youn, August 2006, “New Maximum Power Point Tracker Using Sliding-Mode Observer For Estimation Of Solar Array Current In The Grid-Connected Photovoltaic System", IEEE Transactions On Industrial Electronics, Vol. 53, No.4, pp. 1027-1036.

[6] Jae Ho Lee, Hyun Su Bae, Bo Hyung Cho, Aug 2006,“Advanced Incremental Conductance MPPT Algorithm with a Variable Step Size", Power Electronics and Motion Control Conference, EPE -PEMC 2006. $12^{\text {th }}$ International, pp. $603-607$.

[7] Femia, N.; Petrone, G.; Spagnuolo, G.; Vitelli, M., July 2005, “Optimization of perturb and observe maximum power point tracking method", IEEE Transactions on Power Electronics, Vol. 20, Issue 4, pp. 963- 973.

[8] A.M. Sharaf, Liang Yang, 2005, “An efficient Photovoltaic DC Village Electricity Scheme Using a Sliding Mode Controller", IEEE Conference on Control Applications, , pp 1325-1330.

[9] Femia, N. Petrone, G. Spagnuolo, G. Vitelli, May 2004, "Perturb and Observe MPPT technique robustness improved', IEEE International Symposium on Industrial Electronics, Vol. 2, 4-7, pp. $845-850$ vol. 2

[10] Weidong Xiao; Dunford, W.G., June 2004, "A modified adaptive hill climbing MPPT method for photovoltaic power systems", Power Electronics Specialists Conference, PESC IEEE 35th Annual Vol.3, 20-25 pp. 1957 - 1963

[11] Yushaizad Yusof, Siti Hamizah Sayuti, Muhammad Latif, Zamri Che Wanik, 2004, "Modeling and Simulation of Maximum Power Point Tracker for Photovoltaic System”, National Power \& Energy Conference (PECon) Proceedings, Kuala Lumpur, Malaysia, pp. 88-93.

[12] Eduardo Ortiz, Fang Peng, 2000 “A Novel Method To Estimate The Maximum Power For A Photovoltaic Inverter System”, 35th Annual IEEE Power Electronics Specialists Conference.

[13] Alexis de Medeiros Torres, Fernando Antunes, Fernando Soares, 1998, "An artificial Neural Network-Based Real Time Maximum Power Tracking Controller for connecting a PV System to the grid”, IEEE, 0-7803-4503-7/98 pp. 554-559.

[14] Vietson M. Nguyen and C.Q. Lee, March 1996, "Indirect implementations of sliding-mode control law in buck-type converters“, Applied power electronics conference and Exposition (APSC) Vol 1 pp $111-115 .$.

[15] Hanifi Guldemir, "Sliding Mode Control of DC/DC Boost Converter", Journal of Applied Sciences 5(3), ISSN $1812-5654$. 